\title{
The effect of exercising with manual compression foot pumps, on dialysis efficiency, in patients with end stage renal disease
}

\begin{abstract}
:
Aim: This study aimed to establish if exercising with manual compression foot-pumps, could be used as an intervention to improve dialysis efficacy. A pre test -post test design was used to test the intervention. Subjects were invited to participate in the study depending on whether they fitted the eligibility criteria of the study. Eight weeks after entry into the study pre-test values of dialysis efficacy $(K t / V)$ were established prior to the implementation of an eight-week exercise programme followed by the collection of post intervention dialysis efficacy values. Subjects performed

Kern J, MSc (Physiotherapy)'; Stewart A, PhD²; Becker P, PhD

1 Physiotherapist in private practice.

2 Physiotherapy Department, School of Therapeutic Sciences, Faculty of Health Sciences, University of the Witwatersrand.

${ }^{3}$ Statistician MRC and School of Therapeutic Sciences University of the Witwatersrand. seated heel raises with manual compression foot-pumps on their feet (Venous Anti-stasis Slippers) for 20 continuous minutes per hour for the first three hours of their dialysis sessions (two or three times per week). Twelve subjects finished the programme. During the eight weeks of exercise an increase of $8.7 \%$ was noted in $K t / V$ values with a mean change of 0.12 ( $p=0.04)$. It appears that an eight week exercise programme using manual compression foot pumps (Venous Anti-stasis Slippers) may be effective in improving dialysis efficiency. These findings need to be tested in a study with an appropriate sample size.
\end{abstract}

KEYWORDS: END-STAGE RENAL DISEASE, EXERCISE, MANUAL FOOT PUMPS.

\section{INTRODUCTION}

The first publication on the benefits of exercise during dialysis dates back 20 years and describes a safe and beneficial method of exercising using a cycle ergometer (Painter et al 1986). Since then it has been repeatedly established that exercise is both safe and beneficial and improves the quality of life of patients with end stage renal disease. Exercise training enhances physical ability in all stages of chronic renal failure and lessens the severity of accompanying diseases that renal patients often experience (Takhreem, 2008; Parsons et al, 2004; Moore et al, 1998; Carney et al,1987; Goldberg et al 1986).

Intradialytic exercise (exercise during dialysis) gives similar benefits to exercise off dialysis and is more convenient, improves adherence to training and allows for less time commitment for subjects and medical supervision (Takhreem, 2008; Parsons et al, 2004; Moore et al, 1998; Painter et al, 1986). The efficacy of dialysis is improved with exercise by increasing the perfusion of skeletal muscles (Daul et al, 2004). The improvement in dialysis efficacy is dependent upon the intensity, modality and timing of exercise during dialysis and it is also recommended that exercise be done in the seated position to maintain a normotensive state during fluid removal with dialysis and to ensure that venous and arterial pressures are maintained constant in fistula lines. In addition exercise should be done during the first two to three hours of a dialysis session (Parsons et al, 2004).

Dialysis efficacy is expressed as $\mathrm{Kt} / \mathrm{V}$ which is a dimensionless mathematical representation of serum urea clearance that is calculated clinically by using pre and post-dialysis blood urea concentrations (O'Connor et al, 2002).The fractional clearance is quantitatively defined as $\mathrm{Kt} / \mathrm{V}$ where:

$\mathrm{K}=$ dialyser urea clearance $(\mathrm{ml} / \mathrm{min})$ : $90 \%$ of blood flow rate in high flux dialysers

$\mathrm{t}=$ total treatment time (minutes): hours on dialysis X 60 minutes

$\mathrm{V}=$ urea distribution volume $(\mathrm{ml})$ : weight in $\mathrm{Kg} X \quad 58 \%$ X 1000

(Fresenius Medical Care 2004).

$\mathrm{Kt} / \mathrm{V}$ values greater than 1.2 indicate adequate dialysis and those lower than 1.2 less than adequate dialysis (Cleary and Denman, 2005). Gotch and Sargent (1985) showed that a $\mathrm{Kt} / \mathrm{V}$ value less than 0.8 is associated with a high likelihood of morbidity and/or treatment failure.

Compression foot pumps are widely used to increase perfusion and reduce the risk of post operative venous thrombosis, but are generally used for postoperative patients who are confined to bed for prolonged periods of time (Fleming et al, 2000). Until recently

\section{Correspondence to:}

Prof A Stewart

Physiotherapy Department

School of Therapeutic Sciences

Faculty of Health Science

University of the Witwatersrand

7 York Rd, Parktown

Johannesburg

2193 
they were all electronic, expensive and not suitable for use in seated individuals. Recently however manual compression foot pumps have become available in South Africa, and incorporate a simple but effective mechanism that can significantly increase venous velocity in the lower limbs of seated individuals. So although designed to reduce lower limb swelling and the risk of deep vein thrombosis by improving venous velocity in seated individuals the principles make them well suited for renal patients who sit for periods of four hours, two to three times a week (Endotec International-VASS Technical Manual, 2005). The manual compression foot pump combines in its design the benefits of electronic foot pumps and graduated compression stockings (Endotec International-VASS Technical Manual, 2005). This manual compression foot pump is known as the "Venous Anti Stasis Slipper" (VASS) and incorporates a simple, yet cost effective mechanism that can increase venous velocity in the lower limbs of seated individuals (Endotec International-VASS Technical Manual, 2005).

This study therefore aimed to establish what effect the use of exercise, with manual compression foot pumps (Venous Anti-stasis Slippers) would have on dialysis efficacy $(\mathrm{Kt} / \mathrm{V})$ of patients with end stage renal disease.

\section{METHOD}

A pre test post test design was used to collect data. This consisted of baseline data collection, followed by an eight week exercise intervention period, and post test data collection.

Ethical clearance for the study was obtained from the Committee for Research on Human Subjects of the University of the Witwatersrand. Informed consent was obtained from all subjects in the study and from the hospital manager, the renal clinic manager and the attending nephrologist of the private hospital where the study took place.

The whole population of 34 self-care haemodialysis out-patients who attended two or three dialysis sessions per week, were screened by the attending nephro- logist. All subjects with the following impairments were excluded: subjects with lower limb amputations; severe paralytic and physical disabilities, cognitive impairments, unstable hypertension, congestive heart failure, cardiac arrhythmias, recent myocardial infarction, unstable angina and any patient doing regular physical exercise. Nineteen subjects were then found to be eligible for this study.

\section{PROCEDURE}

The patients selected for this study were then observed for eight weeks. After this eight week stabilization period they then went onto an exercise programme either two or three times per week for eight weeks.

Baseline dialysis efficacy values $(\mathrm{Kt} / \mathrm{V})$ were obtained from analysis of blood results directly before going onto the exercise programme and again at the end of the eight week exercise programme. The blood samples were obtained from the subjects by a nursing sister in the dialysis unit and then sent for analysis to a private pathology laboratory.

Each subject was then issued with a pair of manual compression foot pumps, namely "Venous Anti Stasis Slippers" (VASS) manufactured by Endotec International to wear on their feet while they performed seated heel raises during their dialysis sessions. The "slippers" (foot pumps) were pre-inflated to $50 \mathrm{~mm}$ $\mathrm{Hg}$ (as per the manufacturers' instructions) at the start of each dialysis session and were inspected twice per week for the duration of the study to ensure that there were no leaks or pressure changes. Each subject was issued with a digital stop watch at the beginning of the exercise session to record the total time they exercised with the "slippers" during each dialysis session and times were recorded on a time sheet for each exercise session. Subjects were connected to the dialysis machines as per their usual routines by the renal nurses and were asked to stay in an upright position with their feet flat on the floor for the period they were exercising.

The pre-inflated "slippers" were applied to the subjects' feet by the first author and subjects were instructed to begin exercising rhythmically by alternately raising their heels (seated heel raises) and to ensure that they exerted adequate pressure with downward movements to move air from one "slipper" to the other. The exercise sessions were supervised by the first author and nursing sisters in the unit who had been trained by the first author. The Borg scale was used by each subject to record the intensity of each exercise session and these values as well as heart rates at the beginning and end of each session were recorded in the subjects' exercise diaries but these values were not included in the analysis of data as they were there as checks for the exercise sessions only. Routine blood pressure monitoring continued.

Subjects were asked to exercise for at least 20 minutes per hour of the first three hours of dialysis and to record the total time exercised per session. At the end of each 20 minute session, subjects could rest, remove the slippers and elevate their legs on a low stool in front of them. This procedure was repeated either two to three times per week for the duration of the eight weeks of the study. This was done to accommodate subjects who came in for dialysis twice or three times per week. At the end of this eight week intervention period dialysis efficacy values $(\mathrm{Kt} / \mathrm{V})$ were again recorded from blood samples as described above.

\section{STATISTICAL ANALYSIS}

The significance of the study was set at $\mathrm{p}=0.05$. Descriptive statistics were used to present the data. A repeated measures analysis of variance (ANOVA) with the exercise group (that is the group that exercised two or three times per week) as the between subject factor and with testing time as the within subject factor was undertaken prior to any further analysis. This was done because some patients had exercised twice a week and some three times a week. It was therefore necessary to establish if this made a difference to the outcome of the study. In view of the findings of this analysis (presented below) it was decided to do a simple paired t test comparing pre inter- 
vention with post intervention dialysis efficacy values $(\mathrm{Kt} / \mathrm{V})$ after combining the two exercise groups.

\section{RESULTS}

Nineteen patients with end stage renal disease on dialysis who met the inclusion criteria participated in the study. Two subjects were approved for kidney transplantation after the screening dialysis efficacy values were established, and were subsequently excluded from the study. Another subject was admitted to hospital prior to the intervention and subsequently died. Four of the remaining subjects voluntarily withdrew from the study during the first week of exercise thus leaving a total of 12 subjects who completed the exercise intervention. (See Table 1 for the demographic profile of the 19 subjects who met the eligibility criteria for the study and Table 2 for the dialysis efficacy values $(\mathrm{Kt} / \mathrm{V})$ at screening, pre intervention and post intervention).

\section{DISCUSSION}

The $8.7 \%$ increase in $\mathrm{Kt} / \mathrm{V}$ noted during this study is not consistent with the $15 \%$ increase reported by Kong et al, (1999), who used cycle ergometers. However as neither the intensity of the exercise sessions nor the specifications of the subjects were reported in their study a direct comparison is difficult. Parsons et al (2004) were the only other researchers who conducted a similar eight week exercise intervention using cycle ergometers. They had six subjects who performed cycle ergometry for 15 minutes per hour for the first three hours of dialysis and they did not get a significant increase in Kt/V. They concluded that the intensity, modality and timing of exercise during dialysis should be modified to result in meaningful changes. A subsequent study, (in which the above protocol was modified to exercising three times a week for 30 minutes in each of the first two hours of dialysis), produced an $11 \%$ increase at the end of the first month and remained high (18-19\% for the duration of their programme) (Parsons et al,2006).

The frequency of exercise was not a factor in this study and there was no

Table 1: Demographics profile of study population $(n=19)$.

\begin{tabular}{|c|c|}
\hline Characteristics & $\begin{array}{l}\text { Values } \\
\text { Mean (SD) }\end{array}$ \\
\hline Age (years) & $\begin{array}{l}55.5( \pm 11.39) \\
\text { range } 36-68\end{array}$ \\
\hline Weight (kg) & $\begin{array}{l}74.16( \pm 17.20 \\
\text { range 56-121 }\end{array}$ \\
\hline Number of women & 7 \\
\hline Number of patients with fistulas & 15 \\
\hline $\begin{array}{l}\text { Primary diagnosis } \\
\qquad \begin{array}{l}\text { Diabetic neuropathy } \\
\text { Hypertensive nephrosclerosis } \\
\text { Wegener's granulomatosis } \\
\text { Alport's syndrome }\end{array}\end{array}$ & $\begin{array}{l}8 \\
9 \\
1 \\
1\end{array}$ \\
\hline $\begin{array}{l}\text { Co-morbidities }(\mathrm{n}) \\
\qquad \begin{array}{r}\text { Diabetes mellitus } \\
\text { Cardiac history } \\
\text { Hypertension }\end{array}\end{array}$ & $\begin{array}{l}8 \\
1 \\
12\end{array}$ \\
\hline $\begin{array}{l}\text { Medications } \\
\qquad \begin{array}{l}\text { Erythropoietin } \\
\beta \text { blockers } \\
\text { Angiotensin-converting enzyme inhibitors } \\
\mathrm{Ca}^{2+} \text { channel blockers } \\
\alpha \text { blockers } \\
\mathrm{Fe}^{2+} \text { supplementation }\end{array}\end{array}$ & $\begin{array}{l}19 \\
13 \\
12 \\
8 \\
0 \\
18\end{array}$ \\
\hline $\begin{array}{l}\text { Dialysis prescription } \\
2 \text { days per week } \\
3 \text { days per week } \\
\text { Duration (hours) }\end{array}$ & $\begin{array}{l}5 \\
14 \\
4\end{array}$ \\
\hline Median duration for length of time on dialysis (months) & $\begin{array}{l}16 \\
\text { range 2-44 }\end{array}$ \\
\hline
\end{tabular}

difference between subjects at pre-intervention and post-intervention when frequency of exercise was compared with dialysis efficiency. All other factors namely-dialysate flow rate, the dialysers and the fistula needle sizes were kept constant for the duration of the study, so the resultant $8.7 \%$ increase in $\mathrm{Kt} / \mathrm{V}$ was probably due to the exercise intervention using manual compression foot pumps (Venous Anti stasis Slippers). These results obviously have to be viewed with caution given the fact that this was a pilot study with a small sample size.
Thus in conclusion it appears that an eight week exercise programme using manual compression foot pumps may be effective in improving dialysis efficacy and there seems to be no statistically significant relationship between changes in $\mathrm{Kt} / \mathrm{V}$ and the frequency of exercise. These findings should be confirmed in studies with appropriate sample sizes.

\section{DISCUSSION}

The authors wish to acknowledge statistical help given by Mr E Musenge. 
Table 2: Summary of dialysis efficacy (Kt/V) values.

\begin{tabular}{|c|c|c|c|}
\hline $\begin{array}{l}\text { Subject } \\
\text { number }\end{array}$ & $\begin{array}{l}\text { Screening } \\
\mathrm{Kt} / \mathrm{V} \\
(\mathrm{n}=18)\end{array}$ & $\begin{array}{l}\text { Pre-intervention } \\
\mathrm{Kt} / \mathrm{V} \\
(\mathrm{n}=16)\end{array}$ & $\begin{array}{l}\text { Post-intervention } \\
\mathrm{Kt} / \mathrm{V} \\
(\mathrm{n}=12)\end{array}$ \\
\hline 1 & 2.66 & 2.36 & 2.06 \\
\hline 2 & 2.0 & 1.52 & 1.78 \\
\hline 3 & 2.2 & 1.68 & 1.96 \\
\hline 4 & 2.1 & 1.76 & 1.93 \\
\hline 5 & 0.92 & 0.71 & 0.68 \\
\hline 6 & 1.16 & 1.03 & 1.2 \\
\hline 7 & 1.24 & 1.1 & 1.1 \\
\hline 8 & 1.6 & 1.22 & 1.43 \\
\hline 9 & 1.5 & 1.21 & 1.41 \\
\hline 10 & 1.3 & 1.02 & 1.34 \\
\hline 11 & $\mathrm{~N} / \mathrm{A}$ & 1.98 & 2.1 \\
\hline 12 & 1.2 & 0.97 & 0.97 \\
\hline 13 & 2.29 & 1.48 & Withdrew from study \\
\hline 14 & 1.22 & 1.08 & Withdrew from study \\
\hline 15 & 1.71 & 1.42 & Withdrew from study \\
\hline 16 & 1.86 & 1.65 & Withdrew from study \\
\hline 17 & 2.25 & $\begin{array}{l}\text { Excluded - } \\
\text { Kidney transplant }\end{array}$ & $\mathrm{N} / \mathrm{A}$ \\
\hline 18 & 1.55 & $\begin{array}{l}\text { Excluded - } \\
\text { Kidney transplant }\end{array}$ & $N / A$ \\
\hline 19 & 1.86 & Deceased & $\mathrm{N} / \mathrm{A}$ \\
\hline Mean $( \pm$ SD) & $1.70( \pm 0.48)$ & $1.39( \pm 0.43)$ & $1.50( \pm 0.47)$ \\
\hline
\end{tabular}

Of the 12 subjects who completed the study five exercised twice a week and seven exercised three times a week. There was no statistical difference in dialysis efficacy values $(\mathrm{Kt} / \mathrm{V})$ between the group that exercised twice a week, compared to the group that exercised three times a week.

Table 3: Dialysis efficacy values $(\mathrm{Kt} / \mathrm{V})$ before and after the exercise intervention $(n=12)$.

\begin{tabular}{|l|l|l|l|l|}
\hline Test & Mean Kt/V & $\mathbf{\pm S D}$ & $\mathbf{C l}$ & $\mathbf{p}$ value \\
\hline $\begin{array}{l}\text { Pre } \\
\text { intervention }\end{array}$ & 1.38 & \pm 0.49 & $1.07-1.69$ & \\
\hline $\begin{array}{l}\text { Post } \\
\text { intervention }\end{array}$ & 1.49 & \pm 0.47 & $1.20-1.79$ & $\mathrm{p}=0.04$ \\
\hline
\end{tabular}

Table 3 illustrates the positive improvement in dialysis efficacy values post exercise intervention. During the eight weeks of exercise an increase of $8.7 \%$ was noted in $\mathrm{Kt} / \mathrm{V}$ values with a mean change of $0.12(\mathrm{p}=0.04)$. Thus the eight week intervention resulted in an $8.7 \%$ increase in $\mathrm{Kt} / \mathrm{V}$.

\section{REFERENCES}

Carney RM, Templeton B, Hong BA, Harter HR, Hagberg JM, Schechtman KB, Goldberg AP 1987 Exercise reduces depression and increases performance of pleasant activities in hemodialysis patients. Nephron 47: 194-198

Cleary J, Drennan J 2005 Quality of life of patients on haemodialysis for end stage renal disease Journal of Advanced Nursing 51(6): 577-586

Daul AE, Schafers RF, Daul K, Philipp T 2004 Exercise during haemodialyis Clinical Nephrology 61:S26-S30

Endotec International 2005 venous Anti-stasis Slipper (VASS) -Technical manual USA

Fleming P, Fritzgerald P, Devitt A, Rice J, Murray P 2000 The effect of the position of the limb on venous impulse foot pumps The Journal of Bone and Joint Surgery 82-B: 433-434

Fresenius Medical Care Dialysis Information Guide $2004<$ http;//www.fmc-ag.com Goldberg AP, Geltman EM, Gavin JR, Carney RM, Hagberg JM, Delmaz JA, Naumovich A, Oldfield MH, Harter HR 1986 Exercise training reduces coronary risk and effectively rehabilitates hemodialysis patients Nephron 42:311-316

Gotch FA, Sargent JA 1985 A mechanistic analysis of the National Cooperative Dialysis Study(NCDS) Kidney International 28; 526-534

Kong CH, Tattersall JE, Greenwood RN, Farrington K 1999 The effect of exercise during hemodialysis on solute removal Nephrology Dialysis Transplant 14:2927-2931

Moore GE, Painter PL, Brinker KR, StrayGundersen JS, Mitchell JH 1998 Cardiovascular response to submaximal stationary cycling during hemodialysis American Journal of Kidney Disease 31:631-637

O'Connor AS, Leon JB, Sehgal AR 2002 The relative predictive ability of four different measures of haemodialysis dose American Journal of Kidney Diseases 40:1289-1294

Painter TL, Nelson-Worel J, Hill M, Thornbery D, Shelp W, Harrington A, Weinstein A 1986 Effects of exercise training during hemodialysis Nephron 43:87-92

Parsons TL, Toffelmire EB, King-Van Vlack 2006 Exercise Training During Hemodialysis Improves Dialysis Efficacy and Physical Performance. Archives of Physical Medicine and Rehabilitation 87: 680-687

Parsons TL, Toffelmire EB, King-Van Vlack 2004 The effect of an exercise program during haemodialysis on dialysis efficacy, blood pressure and quality of life in end-stage renal disease (ESRD) patients Clinical Nephrology 61:261-27

Takhreem M 2008 The effectiveness of intradialytic exercise prescription on quality of life in patients with chronic kidney disease The Medscape Journal of Medicine 10(10):226-241. 